\title{
The future ain't what it used to be
}

\author{
Future Proof/You Call This the Future? \\ by Nick Sagan \\ with Mark Frary and Andy Walker \\ Icon Books/Chicago Review Press: 2008. \\ 160 pp. $£ 10.99 / \$ 14.95$
}

Rather than teleporting, or even arriving on a hoverboard, I rode to work this morning on the distinctly nineteenth-century technology of a bicycle on tarmac. Much to the relief of my colleagues, I don't sit at my desk in a silver jumpsuit, and my lunch doesn't come in pill form. As a confirmed sci-fi geek, I am perpetually disappointed that the things promised to me by science fiction have not yet arrived.

Good-quality sci-fi is concerned with the present, our current fears and hopes. The technology imagined either drives plot, such as the human-powered virtual reality of the Matrix movies, or is set-dressing, as in the film Alien - at its core a haunted-house story. Alas, accurate fortune-telling in science fiction is rare. No one really predicted the dominance of the personal computer over our lives, nor that the rather low-tech medium of text-messaging would become such a popular form of communication. As baseball legend Yogi Berra put it: "It's tough to make predictions, especially about the future."

And that is the subject of Nick Sagan's terrific new book. Sagan, a Hollywood screenwriter, carries a healthy pedigree in this field. He's the son of Carl Sagan who, aside from his work as a cosmologist, also wrote some outstanding sci-fi, including Contact. The excellent film version with Jodie Foster in the lead is one of the less fanciful sci-fi films of the 1990s.

Future Proof is the latest in a recent run of guidebooks, such as Daniel H. Wilson's Where's My Jetpack?, about the fictional products imagined by sci-fi's finest creators and how close we are to realizing those phenomena. Sagan's journey includes terraforming by cyborgs and teleporting through wormholes. This snapshot of all the bleeding-edge technology currently available, even though it falls short of the fiction, suggests that human endeavour is a truly glorious thing - one that we too often take for granted. With his co-authors Mark Frary and Andy Walker, Sagan writes casually well. And

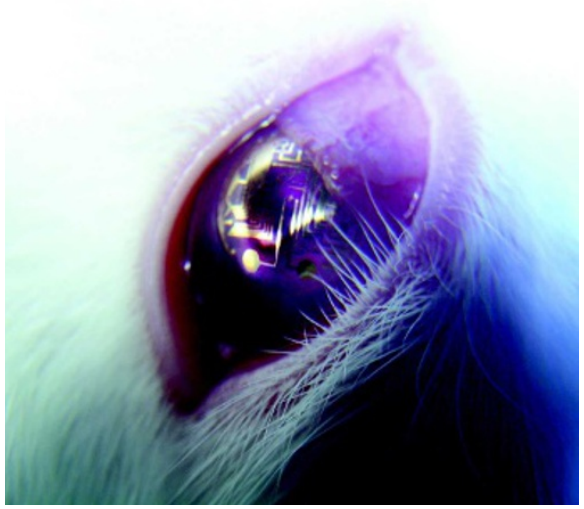

Lenses that can project in-eye displays now exist. the book features handy diagrams and references to all the best twentieth-century sci-fi.

The only trouble is that, by definition, science moves so quickly that some entries in the book are already out of date. For example, Babak Parviz and his colleagues from the University of Washington in Seattle recently announced that they are close to completing a contact lens with embedded light-emitting diodes, the first step towards creating an in-eye display reminiscent of Arnold Schwarzenegger's relentless Terminator. Meanwhile, researchers from Imperial College London have published a paper describing an invisibility cloak — albeit still theoretical, and highly impractical.

Nevertheless, Future Proof is a fun, useful primer for understanding the symbiosis between science and science fiction. Perversely, I hope that this version of the book becomes redundant sooner rather than later.

As an experiment in testing the limitations of a highly futuristic invention, I wrote this review on my iPhone. It's a touch-screen device with so many slick functions that it sometimes feels indistinguishable from magic: when I first turned it on, it creepily showed me where I was standing. I've become accustomed to its ways so quickly that I often find myself smudging non-touch-screens in error. But as a typewriter for a 500-word book review, it was hopeless. I look forward to the day when my children will puzzle and sneer at this crude silicon-based tricorder prototype. Until then, I'm not imaginative or foolish enough to dream up what their essential devices might be.

Adam Rutherford is Nature Publishing Group's Podcast and Video editor.

\section{More cacophony than harmony}

\author{
The World In Six Songs: How the Musical \\ Brain Created Human Nature \\ by Daniel J. Levitin \\ Dutton Books: 2008. 333 pp. $\$ 25.95$
}

Six songs seems a small repertoire to address so grandiose a theme. Yet Daniel Levitin contentiously argues for six classes of song in his quickly published follow-on from This Is Your Brain On Music. He purports to explain neuroscientific concepts by framing them around song themes of friendship, joy, comfort, knowledge, religion and love.

Notwithstanding his claim that he "endeavoured to include examples from music [from] all over the world", Levitin, a recording producer turned academic psychologist, remains tenacious in his devotion to pop music. Granted, he alludes to a love for Beethoven's Pastoral Symphony and mentions Mozart occasionally, but other musical genres seem of far less importance to him. Listing "the musical events that changed the way I would hear for the rest of my life", every one is popular: Sting, Cannonball Adderley and Paul Simon are among his favourites. It would be unthinkable for the author of a book on, say, the 'pictorial brain' or the 'literary brain' to ignore the greatest examples of those arts or to reveal so enthusiastically that his tastes seem not to have matured since his adolescence.

Levitin writes for a US audience of a certain age that has never outgrown its attachment to the music of its youth. There is little in The World in Six Songs to acknowledge those with matured or non-American musical tastes, which creates difficulties when he writes about "us" having "common ground" or indulges in such hyperbole as "our truth detectors go wild". Who, apart from US baby-boomers, might comprise this "us"?

Far from restricting himself to six songs, and setting aside that a different person might classify those songs differently, the author's repertoire of musical examples is vast. His collection of 'friends' seems equally extensive. The text is littered with names - musicians and research academics among them - and their mention often seems calculated to impress rather than enlighten. Every significant thinker in his field sounds like a trusted intimate.

This makes Levitin look fortunate but, even if it were true, makes him intellectually vulnerable. One is unlikely to be critical of the work of such 'friends'. And so it proves. When 